\title{
Partial Diprosopus Bucallis in a Bunaji Heifer in Bauchi State Nigeria: A Case Report

\author{
Ibrahim Abubakar Sadiq ${ }^{1}$, Aliyu Bashir Sa'idu ${ }^{1,2}$, Orakpoghenor Ochuko ${ }^{3 *}$, Hyacinth Ngwu \\ Chijioke', Dahiru Umar' ${ }^{1}$, Adams Auwal Abdullahi ${ }^{1}$
} \\ ${ }^{1}$ State Veterinary Clinic, Ministry of Agriculture and Natural Resources Bauchi, Bauchi State, Nigeria. ${ }^{2}$ Veterinary Surgery and Radiology, Ahmadu Bello University, Zaria, Nigeria. \\ ${ }^{3}$ Veterinary Pathology, Ahmadu Bello University, Zaria, Nigeria. \\ *Corresponding Author: Orakpoghenor Ochuko, Veterinary Pathology, Ahmadu Bello University, Zaria, Nigeria.
}

\section{Abstract}

Diprosopus involves duplication of the facial structures on single body and neck. A one and a halfyear-old Bunaji heifer was presented to the Area Veterinary Clinic, Ran gate, Bauchi State with complaint of accessory structure below the oral cavity. Thorough physical evaluation revealed an incomplete mouth consisting of paired (fused) mandibles with complete dentition, a rudimentary tongue, salivary secretion and bony eminence that projects caudally terminating as a short stumpy bone. This incomplete mouth was attached to the submandibular region of the normal mouth only by skin and muscle tissues. Based on these findings, a diagnosis of diprosopus bucallis was made and surgical management (correction) was recommended. Under local anaesthesia, the accessory mouth was excised and surgical wound was routinely sutured. Post-operative wound management was instituted using antibiotics and analgesics for 7 days. At 10 days post-operatively, sutures were removed and the heifer recovered uneventfully.

Keywords: Diprosopus, Bunaji, heifer, incomplete, mouth, surgical.

\section{INTRODUCTION}

Congenital defects are anatomical and physiological anomalies present at parturition. The anomalies may affect an organ, parts of a system, or an entire system [1]. Diprosopus involves duplication of the facial structures on single body and neck. A rare case of 'partial diprosopus buccallis is reported in one-anda-half-year-old Bunaji heifer that was purchased in a local livestock market in Alkaleri Local Government Area of Bauchi State. The morphological features, surgical correction and/or management of this rare condition are being described in this report.

\section{CASE Report}

A one-and-a-half-year-old Bunaji heifer about 106 kg body weight was presented to the Area Veterinary Clinic, Ran gate Bauchi, Nigeria with the chief complaint of having an extra mouth. Clinical findings revealed slight loss of condition though normal appetite and rough hair coat and normal vital parameters.

Physical examination of the heifer revealed duplicated facial structures (Diprosopus); an additional and a ventral pointing mouth part. The normal/anatomical buccal cavity had all functional structures. This is in contrast to the extra (in complete) buccal cavity which had the following: a stumpy/ rudimentary tongue which retracts inward when pulled (Figure 1; A2), two fused mandibles with complete dentition (Figure 1; B2), premolar and molars of the second jaw (Figure 1 ; C), presence of a bony projection which extend caudally from the fused mandibles and terminated as a short stumpy bone (Figure 1; D); integumentary attachment connecting mandibular lips of the normal mouth to the extra mouth (Figure 1; E), salivary secretion indicating presence of functional salivary gland. The extra incomplete mouth was connected to the floor of the normal mouth (mylohyoid muscle both rostral and caudal part) by means of connective tissues and fold of skin (Figure 1; E) (an extension of the dew lap to the submandibular area) but the oral cavities are not in any way connected. A clinical diagnosis of partial diprosopus buccalis was made. 


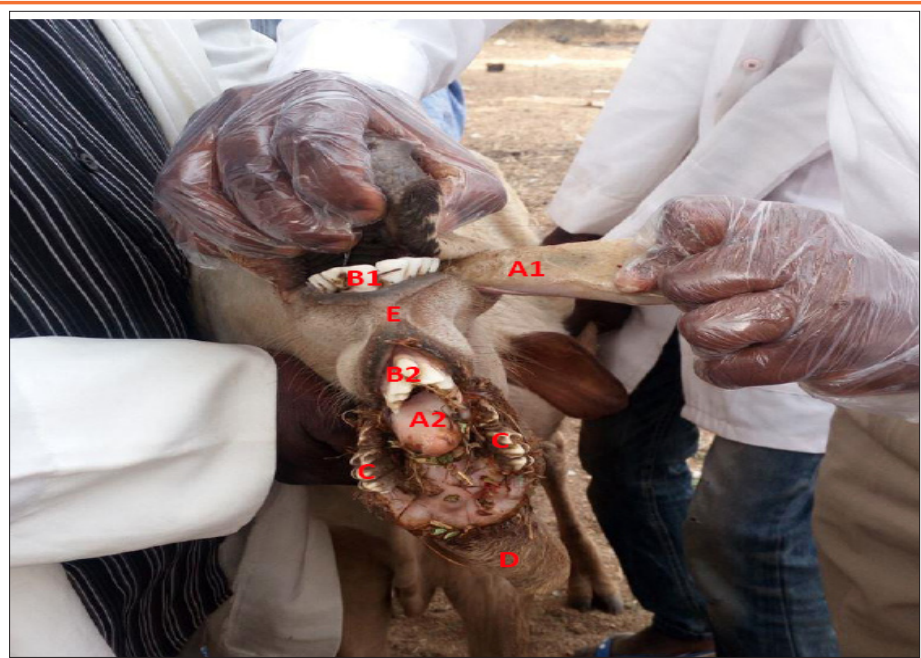

Fig1. Buccal cavity of Diprosopus heifer illustrating duplication of some facial structures; tongue (A1 and $A 2)$, incisors (B1 and B2), premolar and molars of the second jaw C), caudally pointing bony process (D) and integumentary attachment connecting the lower lips of the normal and diprosopus mouth (E).

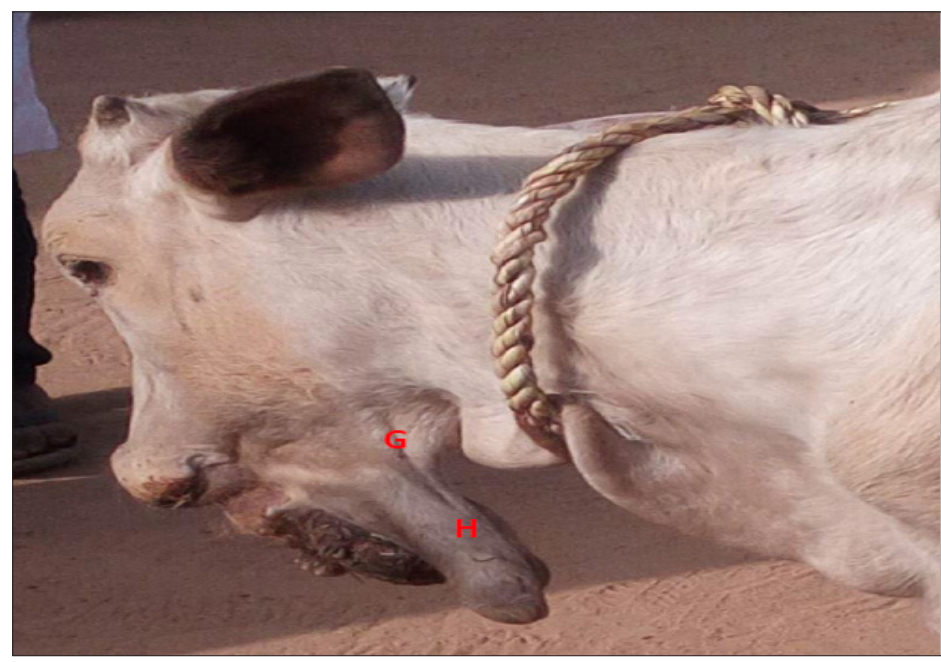

Fig2. Left lateral view of heifer illustrating point of attachment of the partial diprosopus buccal cavity with the point of attachment $(G)$ and backward projection (bony process) $(H)$.

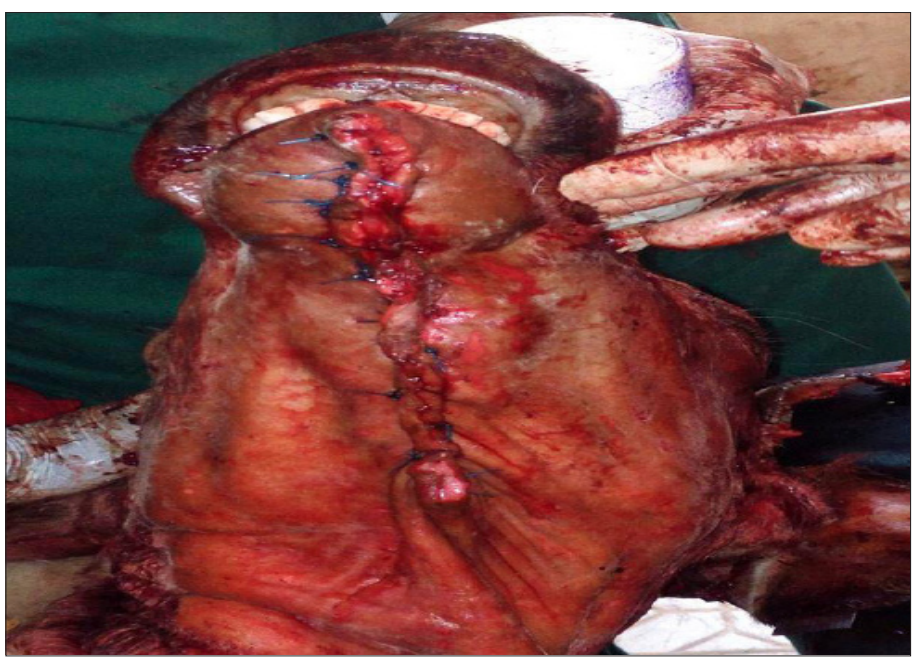

Fig3. Stitched surgical site after a successful procedure. 


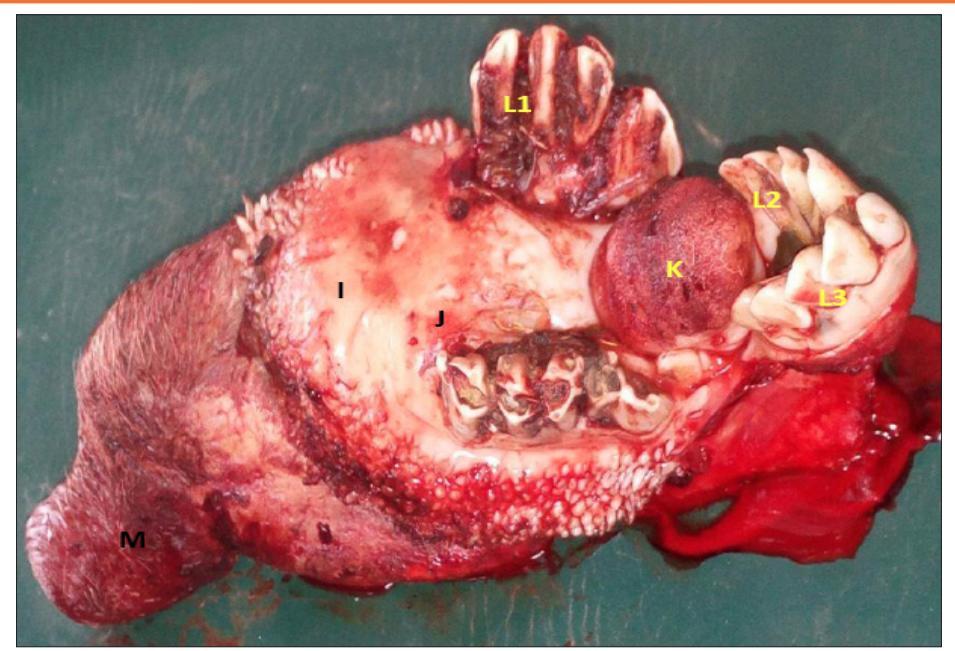

Fig4. Excised duplicated mouth (extra mouth) in situ, showing fused mandibles (I), buccal papillae (J), rudimentary tongue on hard palate (K), complete dentition (L1, L2 and L3) and caudally pointing bony eminence (M).

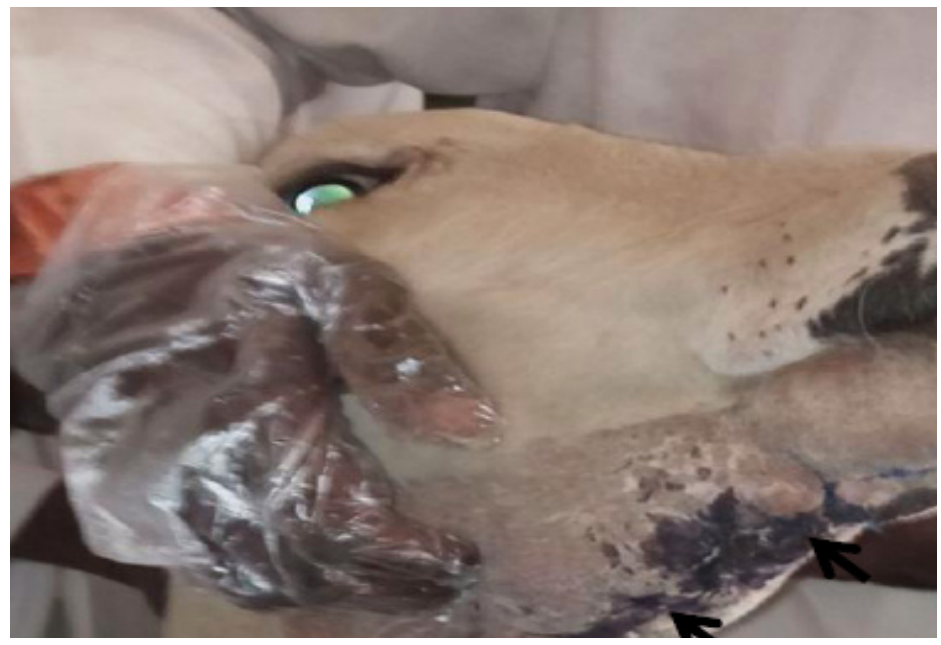

Fig5. Surgical patient 10 days post-surgery. Note the healed/apposed incision line on the skin with tissue scab and mild hair growth around the site (arrows).

\section{MANAGEMENT}

Analysis of these findings established absence of neither osseous nor tubular/visceral connection between the incomplete or diprosopus and the functional mouths. Hence, surgical removal of the extra mouth was recommended, and samples were collected and sent to laboratories as part of presurgical evaluation.

\section{Surgical Procedure}

The proposed surgical site was liberally shaved, scrubbed and aseptically prepared. With the animal on dorsal recumbency, local infiltration of the skin flap and the connective tissue over the proposed line of incision was achieved using $25 \mathrm{mls}$ of $2 \%$ lidocaine HCL+ Adrenaline. Two straight intestinal forceps were applied adjacent to each other around the proposed line of incision to minimize hemorrhages from peripheral blood vessels, which are branches of facial artery and vein. A straight line incision was made, extending from part of dew lap to the point of fusion of the two mandibles. Using gentle pressure, the fused area undermining the skin was severed, bluntly detached from the fused mandibles of the extra mouth to create enough skin flap. Finally, the last point of attachment between the mylohyoid muscles and the fused end of the mandibular bones was dislodged, leaving out an excess flap (including parts of mandibular lip). The surgical wound was closed in two layers; a subcuticular pattern using an absorbable suture material (chromic cat gut, size 1) and finally skin closure was achieved using Nylon suture [size 2/5metric] in a horizontal mattress pattern. Topical antibiotic (oxytetracycline spray) was applied unto incision line. 
Partial Diprosopus Bucallis in a Bunaji Heifer in Bauchi State Nigeria: A Case Report

\section{POST-Surgical CARE}

The animal was placed under close monitoring for a period of 7 days and administration of parenteral antibiotic, wound (surgical site) management and monitoring of vital parameters and the findings were as follows; Procaine benzylpenicilline + dihydrostreptomycine (STREPTOPEN 20/20 DS®, Alfasan WOERDEN-HOLLAND) $2120000 \mathrm{IU}+530 \mathrm{mg}$ IM, oid $\times 7 / 7$; Diclofenac Na (Diclowin ${ }^{\circledR}$, HUBEI TIANYAO PHARM. Co., LTD China) at $2.5 \mathrm{mg} / \mathrm{kg}$ body weight (total dose $265 \mathrm{mg}$ ) IM, oid $\times 3 / 7$; Multivitamins (KC-VIT®, Yeluri Formulations Pvt. LTD) $10 \mathrm{mls}$, IM, oid $\times 3 / 7$ and Oxytetracycline $(3.58 \%$ w/w solution) Cutaneous Spray, topical $\times 7 / 7$ (Softland Oxytetracycline Hcl Spray®, HEBEI HUARUN PHARM. CO., LTD China). Stitches were removed after ten days, having recorded a remarkable progress based on level healing and performance.

\section{Discussion}

Congenital anomalies are the product of errors in embryogenesis (malformations) or the result of intrauterine events that affects embryonic and foetal growth (deformations and disruptions). The more complex in the sequence of events required in the formation of a structure, the more likelihood of malformations in that structure [2]. Congenital head defects involving duplications such as diprosopus, dicephalus and schisoprosopia occur more frequently in cattle than in sheep and pigs, and are rare in goats [3]. The degree of facial duplication varies from a partial doubling of the nostrils and upper jaw to a complete duplication of the face with formation of two mouths, four eyes and four ears [4].

Noden and De Lahunta [1] considered incomplete division of the zygote at a considerably late stage of embryonic development as the reason for congenital duplication like diprosopus. Arthur et al. [5] and De Silva et al. [6] also found out that factors responsible for incomplete separation of the primitive streak after day 13 of fertilization are considered to be responsible for such defects. These factors may be result parental infection with a virus, poison ingestion by the dam, vitamin deficiency, genetic factors and/or combination of these factors. Also, exposure to radiation [7] and aging of the ovum prior to fertilization [8] have been reported to play a major role in causing these defects. Likewise practices like inbreeding or line breeding between parents with history of congenital anomalies will usually result in the expression of the defect in the progeny, as the recessive gene responsible for the defect is homozygous in the inbred parents [9]. Schulze et al. [10] suggested that diprosopus could be an oligogenic inheritance as the parent stock and their ancestors usually show no signs of diprosopus and the frequency of its occurrence in a herd is presumably low.

This might explain our finding in this report as it was gathered that one of the reasons why the actual owner sold the heifer was the fear of passing the unwanted trait (the congenital defect) to its progeny within the herd. It can therefore be inferred from this that the calving record of the dam was free of any of such defect and that the present heifer is likely the first of its kind in the entire herd history. This also conforms with the findings of Potter [11] who linked most diprosopus foetuses to non-hereditary factors, but rather abnormal duplications during gestation.

Incidence of congenital defects among calves ranges from 1.2-3.0 \%, with 40-50 \% born dead [12]. Salami et al. [4] reported that most pregnancies involving fetal monsters do not continue to term since obstetrical difficulties, usually culminating in dystocia or still births emerge, resulting in foetus becoming unable to adjust to normal posture prior to parturition. Some that were lucky to be delivered alive or even aborted usually died shortly after. This is in contrast to the present finding as the animal survived up to one and a half years and the anomaly was corrected surgically. This could be so since most cases of partial diprosopus as suggested by Wu et al. [13] are associated with fewer anomalies, and the prognosis are better than those involving complete duplication of facial structures.

\section{ConCLUSION}

Conclusively, it could be inferred from this report that not all congenital defects should be left unmanaged or untreated especially when the level of prognosis is properly assessed. Therefore, surgical interventions should be attempted in such cases of diprosopus involving only partial duplications (as in the present case) when it has been established that there isn't any osseous or CNS connection to the duplicated structure(s). It is advised that livestock farmers be sensitized on ways to avert such defects/abnormalities since by reducing the frequency of inbreeding as well as culling any parent stock with history of producing diprosopus calf, incidence of such occurrences may invariably be lowered. 


\section{REFERENCES}

[1] Noden DM, De Lahunta A. The embryology of domestic animals: developmental mechanisms and malformations. Williams and Wilkins, Baltimore 1985, pp.109-152.

[2] Jones KL. Dysmophology approach and classification. In: Smith's recognizable patterns of human malformation, $6^{\text {th }}$ ed, Elsevier Saunders, Philadelphia 2006, pp. 1 .

[3] Hiraga T, Dennis SM.1993. Congenital duplication. In: Dennis SM (ed.). The Veterinary Clinics of North America, Food Animal Practice. Congenital Abnormalities. Saunders, Philadelphia 1993, pp. 145-161.

[4] Salami OS, Okaiyeto SO, Danbirni S, Ibe C, Allam L, Kudi CA. [2011]: A case of diprosopus monauchenos in a day old calf (White Fulani $\times$ Friesian cross) in an integrated dairy farm. Global Science Research Journals 2011, 1(1):049-052.

[5] Arthur GH, Noakes DE, Pearson H, Parkinson TJ. Veterinary Reproduction and Obstetrics, 8th ed. W.B. Saunders Co. Ltd., London 2001.

[6] DeSilvaHJ,SamarawickremaNA,Wickremasinghe AR. Toxicity due to organophosphorus compounds: what about chronic exposure? Trop Med Hyg 2006, 100: 803-806.
[7] Juberg RC. (1983). Origin of chromosomal abnormalities: Evidence for delayed fertilization in meiotic non disjunction. Hum Genet 1983, 64:122-127.

[8] Tarin JJ, Perez-Albala S, Cano A. Consequences on offspring from abnormal function in aging gametes. Hum Reprod 2000, Update, 6: 532-549.

[9] Olsen TA. Cattle Genetics in: The Inheritance of Genetic Defects - Part 3. 2008, Accessed online at http://www.braunviehcenter.com/cattle_genetics_ part3.html. 10-06-2010 by 11:13:32 GMT.

[10] Schulze U, Kuiper H, Doeleke R, Ulrich R, Gerdwilker A, Distl O. Familial occurrence of diprosopus in German Holstein calves. Berliner und Munchener Tierarztliche Wochenschrift 2006, 119: 251-257.

[11] Potter EL. Pathology of foetus and infant. $2^{\text {nd }} E d$. Yearbook. Med. Publicers, Chicago 1961.

[12] Leipold HW, Dennis SM. Congenital defects affecting Bovine production. In: Current therapy in Theriogeneology, diagnosis, treatment and prevention of reproductive diseases in small and large animals, Marrow (ed), W.B. Saunders Company, Philadelphia 1986, pp.177-199.

[13] Wu J, Staffenberg DA, Mulliken JB, Shanske AL. Diprosopus: A unique case and review of the literature. Teratology 2002, 66: 282-287.

Citation: Ibrahim Abubakar Sadiq, Aliyu Bashir Sa'idu, Orakpoghenor Ochuko, et.al. Partial Diprosopus Bucallis in a Bunaji Heifer in Bauchi State Nigeria: A Case Report. Archives of Dentistry and Oral Health. 2020; 3(1): 21-25.

Copyright: (C) 2020 Ibrahim Abubakar Sadiq, Aliyu Bashir Sa'idu, Orakpoghenor Ochuko, et.al. This is an open access article distributed under the Creative Commons Attribution License, which permits unrestricted use, distribution, and reproduction in any medium, provided the original work is properly cited. 